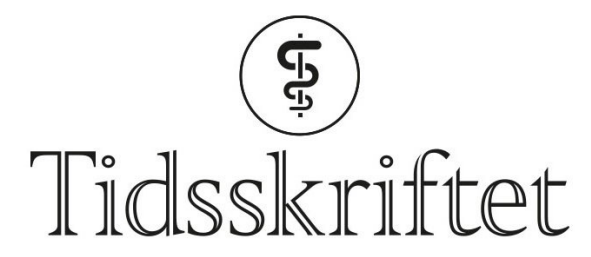

DEN NORSKE LEGEFORENING

\title{
Oppmøte i Mammografiprogrammet blant innvandrere og norskfødte kvinner
}

ORIGINALARTIKKEL

SAMEER BHARGAVA

E-post: sambha@vestreviken.no

Kreftseksjonen

Medisinsk avdeling

Bærum sykehus, Vestre Viken

og

Kreftregisteret

Sameer Bhargava er ph.d. og seksjonsoverlege. Som ph.d.-stipendiat var han ansatt ved Kreftregisteret, der han nå er postdok, og tok sin doktorgrad i Mammografiprogrammet.

Forfatteren har fylt ut ICMJE-skjemaet og oppgir ingen interessekonflikter.

\section{GUNHILD MANGERUD}

Mammografiseksjonen

Kreftregisteret

Gunhild Mangerud har mastergrad i folkehelse og er rådgiver i Mammografiprogrammet.

Forfatteren har fylt ut ICMJE-skjemaet og oppgir ingen interessekonflikter.

\section{SOLVEIG HOFVIND}

Mammografiseksjonen

Kreftregisteret

og

Institutt for naturvitenskapelige helsefag

OsloMet - storbyuniversitetet

Solveig Hofvind er ph.d., leder for Mammografiprogrammet og professor i radiografi.

Forfatteren har fylt ut ICMJE-skjemaet og oppgir ingen interessekonflikter.

\section{BAKGRUNN}

Kvinner bosatt i Oslo har hatt lavere oppmøte i Mammografiprogrammet enn landsgjennomsnittet. Vi utforsket oppmøtet i Mammografiprogrammet blant innvandrere versus norskfødte kvinner i Oslo sammenlignet med de andre fylkesområdene i Norge. 
Vi koblet oppmøtedata fra Mammografiprogrammet til sosiodemografiske data fra Statistisk sentralbyrå for 885979 kvinner tilbudt mammografiscreening i perioden 1996-2015. Vi utførte deskriptive analyser av oppmøte i de ulike fylkesområdene for de inviterte kvinnene samlet, for norskfødte og for innvandrere etter fødeland («Vest-Europa, Nord-Amerika, Australia og New Zealand» og «øvrige land»). Videre beregnet vi predikert sannsynlighet for oppmøte med en logistisk regresjon med oppmøte (ja/nei) som utfallsvariabel. Uavhengige variabler i modellen var bosted (Oslo / andre fylkesområder), fødeland og en interaksjon mellom disse variablene. I tillegg justerte vi for alder ved invitasjon, utdanning og sivilstatus.

\section{RESULTATER}

Blant kvinner bosatt i Oslo var oppmøtet $67 \%$ blant norskfødte kvinner, $61 \%$ blant kvinner født i Vest-Europa, Nord-Amerika, Australia og New Zealand, og 39 \% blant kvinner født i «øvrige land». Blant kvinner bosatt utenfor Oslo var tilsvarende oppmøtetall henholdsvis $79 \%, 71 \%$ og $50 \%$.

\section{FORTOLKNING}

Bosted Oslo var assosiert med lavere oppmøte i Mammografiprogrammet, særlig for innvandrerkvinner fra «øvrige land», og uavhengig av justering for mulig konfunderende variabler.

Brystkreft er den vanligste kreftformen blant kvinner og blant de hyppigste årsakene til kreftdød i Norge (1). Mammografiscreening er et sekundærforebyggende helsetiltak, hvor målsettingen er å redusere dødeligheten av brystkreft gjennom å påvise og behandle sykdommen i et tidlig stadium. Europeiske retningslinjer for kvalitetssikring av brystkreftscreening og diagnostikk inkluderer prosessindikatorer som brukes for å vurdere om gjennomføringen av screeningprogrammer er av en slik kvalitet at det potensielt kan gi en dødelighetsreduksjon i målgruppen, og 70 \% har vært definert som akseptabelt nivå for indikatoren oppmøte (2).

Mammografiprogrammet administreres av Kreftregisteret på oppdrag fra Helse- og omsorgsdepartementet. Gjennom programmet får alle kvinner i Norge i alderen 50-69 år, uavhengig av fødeland, tilbud om mammografiscreening annethvert år. Eventuelle tilleggsundersøkelser, diagnostikk og behandling utføres på ett av landets 16 brystdiagnostiske sentre (17 sentre fra 1.1.2020). Oppmøtet blant de inviterte kvinnene har vært på om lag $75 \%$ siden programmets oppstart i 1996, men har variert fra $62 \%$ i Oslo til 82 \% Sogn og Fjordane (3). Andelen innvandrerkvinner som har møtt i

Mammografiprogrammet, har vært betydelig lavere enn andelen norskfødte kvinner (4). Tilsvarende resultater finnes i studier fra andre land om oppmøte til mammografiscreening i urbane versus rurale områder og blant innvandrerkvinner versus ikke-innvandrere (5-9).

En tredel av befolkningen i Oslo er innvandrere eller norskfødte med innvandrerforeldre, en andel som er dobbelt så høy som landsgjennomsnittet (10). Vi vet ikke om oppmøtet i Mammografiprogrammet blant innvandrere varierer med fylkesområde, eller om den høye innvandrerandelen kan forklare noe av årsaken til det lave oppmøtet i Oslo. Hensikten med denne studien var å utforske oppmøte i Mammografiprogrammet blant innvandrere og norskfødte kvinner i Oslo versus i de andre fylkesområdene i Norge.

\section{Materiale og metode}

\section{DATAGRUNNLAG}

Vi mottok opplysninger fra Kreftregisteret om invitasjoner og oppmøte i Mammografiprogrammet for alle kvinner i målgruppen for perioden 1996-2015. 
Opplysninger om fødeland, utdanning og sivilstatus ble hentet fra Statistisk sentralbyrå. Data fra Kreftregisteret ble koblet til data fra Statistisk sentralbyrå på individnivå. Studien hadde tilråding fra Regional komité for medisinsk og helsefaglig forskningsetikk (2013/795). Tidligere har vi undersøkt oppmøte etter fødeland (4) og sosiodemografiske faktorer (11) samt screeningparametere og tumorkarakteristikk blant kvinner som møter til mammografiscreening (12), ved å bruke samme studiepopulasjon som i denne studien.

\section{DEFINISJONER}

Vi refererer til områdene dekket av de 16 brystdiagnostiske sentrene som «fylkesområder». Hvert brystdiagnostiske senter har et nedslagsfelt som i stor grad følger fylkesgrensene fra før 2020, med unntak av Trøndelag (Nord- og Sør-Trøndelag), Agder (Aust- og Vest-Agder), Troms og Finnmark (Troms og Finnmark), Vestre Viken (Buskerud, Asker og Bærum) og Akershus (Romerike og Follo) (13).

Vi benyttet Statistisk sentralbyrås definisjon av innvandrere: Personer født i utlandet av to utenlandsfødte foreldre og fire utenlandsfødte besteforeldre (14). Videre delte vi innvandrerkvinnene i to grupper basert på fødeland: innvandrere født i Vest-Europa, NordAmerika, Australia og New Zealand, og innvandrere født i «øvrige land» (se appendiks 1). Inndelingen vår tilsvarer den mye brukte, men upresise, inndelingen i «vestlige» og «ikkevestlige» land, og ble valgt ettersom ulike sosiodemografiske faktorer som inntekt, utdanning og yrkesstatus samt pre- og postmigratoriske forhold varierer mellom de nevnte gruppene på gruppenivå. Videre varierer forekomsten av brystkreft geografisk - kvinner i såkalt ikke-vestlige land har lavere forekomst av brystkreft enn andre kvinner, noe som kan tenkes å påvirke kjennskap til brystkreft og oppmøte til screening for innvandrere fra disse landene (15).

Utdanning ble definert som det høyeste utdanningsnivået registrert for hver enkelt kvinne frem til 2015 og kategorisert som grunnskole, videregående skole, høyskole/universitet inntil fire år, høyskole/universitet mer enn fire år eller ingen / ikke oppgitt. Sivilstatus ble kategorisert som gift/partner, enke, skilt eller ugift. Alder ble kategorisert i følgende grupper: < 55 år, 55-59 år, 6o-64 år og > 64 år. Oppmøte ble definert som deltakelse i Mammografiprogrammet som følge av utsendt invitasjon og eventuell påminnelse.

\section{STATISTISKE ANALYSER}

Vi utførte deskriptive analyser av oppmøteandelen for innvandrere og norskfødte kvinner bosatt i ulike fylkesområder, og av andelen invitasjoner sendt til innvandrerkvinner av alle utsendte invitasjoner. Logistisk regresjon ble brukt for å analysere oddsen for å møte til screening. Gjentatt oppmøte ble håndtert ved å spesifisere korrelasjonsstrukturen slik at avhengighet mellom kvinner var tillatt. Modell 1 inkluderte fødeland, bosted Oslo / andre fylkesområder og interaksjon mellom disse to variablene. I modell 2 ble det i tillegg justert for alder, utdanning og sivilstatus. Vi brukte STATA/MP 14.1 til alle analysene.

\section{Resultater}

I studieperioden sendte Kreftregisteret 513641 invitasjoner til 106795 kvinner bosatt i Oslo, og 3540050 invitasjoner til 779184 kvinner i de øvrige fylkesområdene (tabell 1). Andelen innvandrerkvinner var $17 \%$ (18 639/106 795) i Oslo og 7 \% (53 568/779 184) i resten av landet.

\section{Tabell 1}

Antall kvinner invitert til Mammografiprogrammet, antall invitasjoner og andel invitasjoner sendt til innvandrerkvinner i perioden 1996-2015 i 16 fylkesområder. 


\begin{tabular}{|c|c|c|c|c|c|}
\hline \multirow[t]{2}{*}{ Fylkesområde } & \multirow{2}{*}{$\begin{array}{r}\text { Inviterte } \\
\text { kvinner, } n \\
(\% \text { av alle } \\
\text { inviterte) }\end{array}$} & \multirow{2}{*}{$\begin{array}{r}\text { Utsendte } \\
\text { invitasjoner, } n \\
(\% \text { av alle } \\
\text { invitasjoner })\end{array}$} & \multicolumn{3}{|c|}{$\begin{array}{l}\text { Andel utsendte invitasjoner til } \\
\text { innvandrere fra ... (\%) }\end{array}$} \\
\hline & & & $\begin{array}{l}\text { Alle } \\
\text { land }\end{array}$ & $\begin{array}{r}\text { Vest-Europa, } \\
\text { Nord-Amerika, } \\
\text { Australia og New } \\
\text { Zealand }\end{array}$ & $\begin{array}{r}\text { "Øvrige } \\
\text { land" }\end{array}$ \\
\hline Oslo & 106795 (12) & 513641 (13) & 15 & 5 & 11 \\
\hline Østfold & $50315(6)$ & $220079(5)$ & 7 & 3 & 4 \\
\hline Akershus & 94307 (11) & $435686(11)$ & 8 & 4 & 4 \\
\hline Hedmark & $35142(4)$ & $144328(4)$ & 5 & 2 & 2 \\
\hline Oppland & 35027 (4) & $151843(4)$ & 4 & 2 & 2 \\
\hline Vestfold & 40591 (5) & $157591(4)$ & 6 & 3 & 3 \\
\hline Telemark & $33650(4)$ & $158753(4)$ & 5 & 2 & 3 \\
\hline Agder & $49543(6)$ & $227352(6)$ & 6 & 3 & 3 \\
\hline Rogaland & 76332 (9) & $373689(9)$ & 6 & 3 & 3 \\
\hline Hordaland & $86561(10)$ & 433111 (11) & 4 & 2 & 3 \\
\hline $\begin{array}{l}\text { Sogn og } \\
\text { Fjordane }\end{array}$ & $18280(2)$ & 75223 (2) & 4 & 2 & 2 \\
\hline $\begin{array}{l}\text { Møre og } \\
\text { Romsdal } \\
\end{array}$ & 42805 (5) & $173738(4)$ & 4 & 1 & 2 \\
\hline Trøndelag & $73595(8)$ & $321633(8)$ & 4 & 2 & 2 \\
\hline Nordland & $43130(5)$ & $183482(5)$ & 3 & 2 & 2 \\
\hline $\begin{array}{l}\text { Troms og } \\
\text { Finnmark } \\
\end{array}$ & $42064(5)$ & $193110(5)$ & 5 & 3 & 2 \\
\hline Vestre Viken & $57842(7)$ & $290432(7)$ & 8 & 4 & 5 \\
\hline Total & $\begin{array}{r}885979 \\
(100,0) \\
\end{array}$ & $\begin{array}{r}4053691 \\
(100,0)\end{array}$ & 7 & 3 & 4 \\
\hline
\end{tabular}

Både innvandrere og norskfødte kvinner hadde lavere oppmøte i Oslo enn i alle andre fylkesområder (tabell 2). Innvandrere, spesielt de som var født i «øvrige land», hadde lavere oppmøte enn norskfødte kvinner i alle fylkesområdene. Blant kvinner bosatt i Oslo var oppmøtet $67 \%$ blant norskfødte kvinner, 61 \% blant kvinner fra Vest-Europa, Nord-Amerika, Australia og New Zealand, og $39 \%$ blant kvinner fra «øvrige land». Blant kvinner bosatt utenfor Oslo var oppmøtet 79 \% blant norskfødte kvinner, 71 \% blant kvinner fra Vest-Europa, Nord-Amerika, Australia og New Zealand, og 50 \% blant kvinner fra «øvrige land» (tabell 3).

\section{Tabell 2}

Oppmøte (\%) blant alle invitasjoner sendt til alle kvinner, norskfødte kvinner og innvandrerkvinner i 16 fylkesområder i Mammografiprogrammet i perioden 1996-2015.

\begin{tabular}{|c|c|c|c|c|c|}
\hline \multirow[t]{2}{*}{ Fylkesområde } & \multirow{2}{*}{$\begin{array}{r}\text { Alle } \\
\text { kvinner }\end{array}$} & \multirow{2}{*}{$\begin{array}{l}\text { Norskfødte } \\
\text { kvinner- }\end{array}$} & \multicolumn{3}{|c|}{ Innvandrere fra ... } \\
\hline & & & $\begin{array}{l}\text { Alle } \\
\text { land }\end{array}$ & $\begin{array}{r}\text { Vest-Europa, } \\
\text { Nord-Amerika, } \\
\text { Australia og New } \\
\text { Zealand }\end{array}$ & $\begin{array}{l}\text { "Øvrige } \\
\text { land" }\end{array}$ \\
\hline Oslo & 64 & 67 & 46 & 61 & 39 \\
\hline Østfold & 74 & 76 & 58 & 70 & 48 \\
\hline Akershus & 76 & 77 & 60 & 71 & 49 \\
\hline Hedmark & 71 & 71 & 58 & 65 & 49 \\
\hline Oppland & 74 & 74 & 56 & 67 & 45 \\
\hline Vestfold & 75 & 76 & 59 & 70 & 49 \\
\hline Telemark & 77 & 78 & 59 & 71 & 49 \\
\hline Agder & 80 & 81 & 62 & 74 & 52 \\
\hline Rogaland & 85 & 86 & 62 & 72 & 53 \\
\hline Hordaland & 82 & 83 & 62 & 74 & 53 \\
\hline Sogn og Fjordane & 83 & 84 & 60 & 68 & 53 \\
\hline
\end{tabular}




\begin{tabular}{|lccrrr|}
\hline Fylkesområde & $\begin{array}{r}\text { Alle } \\
\text { kvinner }\end{array}$ & $\begin{array}{r}\text { Norskfødte } \\
\text { kvinner }\end{array}$ & $\begin{array}{r}\text { Alle } \\
\text { land }\end{array}$ & $\begin{array}{r}\text { Vest-Europa, } \\
\text { Nord-Amerika, } \\
\text { Australia og New } \\
\text { Zealand }\end{array}$ & $\begin{array}{r}\text { "Øvrige } \\
\text { land }\end{array}$ \\
\hline Møre og Romsdal & 73 & 74 & 53 & 61 & 48 \\
\hline Trøndelag & 79 & 79 & 57 & 69 & 49 \\
\hline Nordland & 82 & 82 & 62 & 70 & 53 \\
\hline $\begin{array}{l}\text { Troms og } \\
\text { Finnmark }\end{array}$ & 81 & 82 & 62 & 71 & 51 \\
\hline Vestre Viken & 76 & 78 & 59 & 71 & 50 \\
\hline Total & 76 & 78 & 56 & 69 & 47 \\
\hline
\end{tabular}

\section{Tabell 3}

Predikert sannsynlighet (\%) og 95\%-konfidensintervall (KI) for oppmøte for mulige kombinasjoner av bosted og fødeland. Modell 1 inkluderer bosted og fødeland og interaksjon mellom disse. Modell 2 inkluderer i tillegg alder, utdanning og sivilstatus.

\begin{tabular}{|lcccc|}
\hline Fødeland & \multicolumn{2}{c|}{ Modell 1 } & \multicolumn{1}{c|}{ Modell 2 } \\
\cline { 2 - 5 } & Oslo & $\begin{array}{c}\text { Andre } \\
\text { fylkesområder }\end{array}$ & Oslo & $\begin{array}{c}\text { Andre } \\
\text { fylkesområder }\end{array}$ \\
\hline Vest-Europa, Nord- & 61 (KI & 71 (KI 70 til 71) & $62(\mathrm{KI}$ & 71 (KI 70 til 71) \\
Amerika, Australia og & 60 til & & 64 til & \\
New Zealand & $62)$ & & $47(\mathrm{KI}$ & 55 (KI 55 til 56) \\
\hline "Øvrige land» & $39(\mathrm{KI}$ & 50 (KI 50 til 51) & 46 til & \\
& $39 \mathrm{til}$ & & $47)$ & \\
& $40)$ & & $69(\mathrm{KI}$ & 79 (KI 79 til 79) \\
\hline Norskfødte & $67(\mathrm{KI}$ & $79(\mathrm{KI} 79$ til 79) & 69 til & \\
& $67 \mathrm{til}$ & & $69)$ & \\
\hline
\end{tabular}

Justert for alder, utdanning og sivilstatus var predikert sannsynlighet for oppmøte $69 \%$ blant norskfødte kvinner bosatt i Oslo, 62 \% blant kvinner fra Vest-Europa, Nord-Amerika, Australia og New Zealand bosatt i Oslo, og 47 \% blant kvinner født i «øvrige land» bosatt i Oslo.

Kvinner i aldersgruppen 6o-64 år, kvinner med inntil fire års høyere utdanning på høyskole eller universitet og gifte kvinner hadde høyere oppmøte enn andre kvinner (se tabell 4 i appendiks 2).

\section{Diskusjon}

Vår studie viste at innvandrere, særlig de fra «øvrige land» (land utenfor Vest-Europa, NordAmerika, Australia og New Zealand), hadde lavere oppmøte i Mammografiprogrammet enn norskfødte kvinner i alle fylkesområder i perioden 1996-2015. Oppmøtet var lavere i Oslo enn i andre fylkesområder både for norskfødte kvinner og de to innvandrergruppene.

Funnene er i overensstemmelse med resultater fra tidligere studier fra Mammografiprogrammet (studieperiode 1996-2015) og Livmorhalsprogrammet (studieperiode 2008-12) som også har vist lavere oppmøte blant innvandrerkvinner enn blant norskfødte kvinner $(4,16)$. Sosiodemografiske faktorer som utdanning og sivilstatus er vist å ha betydning for oppmøte, både for innvandrere og norskfødte kvinner (11). Våre funn støtter studieresultater fra Danmark og Sverige som har vist lavere oppmøte blant kvinner som er ugift eller bor alene og har lang, høyere utdanning eller kun grunnskole (5, $6)$.

Resultatene fra denne studien har betydning i et folkehelseperspektiv. De viser at innvandrerkvinner, uansett fødeland og bosted, hadde lavt oppmøte til en forebyggende 
helseundersøkelse som som er anbefalt til kvinner i Norge i alderen 50-69 år uavhengig av fødeland og bosted. Kvinner bosatt i Oslo hadde lavt oppmøte, uansett fødeland. Dette er relevant ettersom innvandrerandelen er høyere i Oslo enn i andre fylker, og eventuelle negative faktorer relatert til bosted Oslo dermed kan ramme innvandrere i større grad enn norskfødte kvinner.

Grupper av innvandrere er vist å ha høyere forekomst av diabetes, hiv, tuberkulose, fysisk inaktivitet, overvekt og røyking - sykdommer og tilstander hvor forebygging og tidlig deteksjon er viktig (17). Fastlegen spiller en viktig rolle i håndteringen av de nevnte sykdommene og tilstandene, og studier har vist at grupper av innvandrere oppsøker fastlege sjeldnere enn norskfødte personer (18). Studier som denne, sammen med kvalitative studier, kan bidra til økt forståelse av bakenforliggende årsaker til ulikheter i helsesøkende atferd.

Under den pågående covid-19-pandemien har ulikheter i sosiodemografiske forhold, kommunikasjonsutfordringer og tillit til offentlige myndigheter blitt trukket frem som medvirkende årsaker til høyere forekomst og verre utfall av covid-19 blant «ikke-vestlige» innvandrergrupper enn andre (19). Det kan tenkes at de samme faktorene også bidrar til det lave oppmøtet blant innvandrere fra «øvrige land» beskrevet i denne studien.

Vi tror årsakene til variasjoner i oppmøte er ulike og sammensatte. Variasjoner i helsekompetanse og kjennskap til brystkreft og screening kan tenkes å være relevant. Informasjon om forebyggende helsetiltak som er ment for hele befolkningen, bør tilpasses alle, også grupper som har utfordringer med helsekompetanse, inkludert innvandrere og personer uten høyere utdanning, samt personer med lang, høyere utdanning (20). Offentlig statistikk viser at det ikke bare er innvandrerandelen som er større i Oslo enn i andre fylker, men også andelen aleneboende og andelen med lang, høyere utdanning (21, 22). Videre er innvandrere fra «øvrige land» født i land med relativt lavere forekomst av brystkreft (15). Det kan derfor tenkes at tilbudet om mammografiscreening oppleves som mindre relevant for dem enn for andre kvinner. Sammen med økt tilgang til private klinikker i hovedstaden kan de nevnte faktorene tenkes å ha bidratt til lavere oppmøte i Mammografiprogrammet blant kvinner i Oslo enn blant kvinner i andre fylkesområder.

Våre metodiske valg hadde noen begrensninger. Den grove inndelingen av innvandrere i to grupper tok ikke hensyn til de store forskjellene i oppmøte blant innvandrerkvinner fra ulike land (4).Vi har kun data som binder fødeland til oppmøte i perioden 1996-2015, mens de siste års resultater fra Mammografiprogrammet viser en generell økning i oppmøte. Oppdaterte data vil kunne gi oss svar på om økningen gjelder både for innvandrere og norskfødte kvinner. Våre fylkesområder var basert på fylkesinndelingene gjeldende frem til 2020. Vi mener at en tilnærming med dagens fylkesgrenser ikke ville ha hatt vesentlig betydning for resultatene og målsettingen med denne studien. Vår studie begrenses også av at det er faktorer vi ikke hadde tilgang til, som kan tenkes å påvirke oppmøte, for eksempel premigratoriske faktorer, bruk av private klinikker og postmigrasjonsvansker.

\section{KONKLUSJON}

Kvinner bosatt i Oslo hadde lavere oppmøte i Mammografiprogrammet enn kvinner i alle andre fylkesområder, uavhengig av om de var innvandrere eller ikke. Bosted Oslo var mer negativt for oppmøte blant innvandrerkvinner født utenfor Vest-Europa, Nord-Amerika, Australia og New Zealand enn blant andre kvinner.

\section{HOVEDFUNN}

Oppmøtet i Mammografiprogrammet var lavere i Oslo enn i andre fylkesområder, både blant innvandrere og norskfødte kvinner.

Bosted Oslo var sterkest assosiert med lavt oppmøte blant kvinner født i land utenfor Vest- 


\section{LITTERATUR:}

1. Cancer in Norway 2018 - Cancer incidence, mortality, survival and prevalence in Norway. Oslo: Kreftregisteret, 2019. https://www.kreftregisteret.no/globalassets/cancer-in-norway/2018/cin2018.pdf Lest 17.11.2020.

2. Perry N, Broeders M, de Wolf C et al. European guidelines for quality assurance in breast cancer screening and diagnosis. Fourth edition - summary document. Ann Oncol 2008; 19: 614-22.

3. Sebuødegård S, Sagstad S, Hofvind S. Oppmøte i Mammografiprogrammet. Tidsskr Nor Legeforen 2016; 136: 1448-51. [PubMed][CrossRef]

4. Bhargava S, Tsuruda K, Moen K et al. Lower attendance rates in immigrant versus non-immigrant women in the Norwegian Breast Cancer Screening Programme. J Med Screen 2018; 25: 155-61.

[PubMed][CrossRef]

5. Jensen LF, Pedersen AF, Andersen B et al. Identifying specific non-attending groups in breast cancer screening-population-based registry study of participation and socio-demography. BMC Cancer 2012; 12: 518. [PubMed][CrossRef]

6. Lagerlund M, Maxwell AE, Bastani R et al. Sociodemographic predictors of non-attendance at invitational mammography screening-a population-based register study (Sweden). Cancer Causes Control 2002; 13: 73-82. [PubMed][CrossRef]

7. Screening and immunisations team health and social care information centre. Breast Screening Programme, England. Statistics for 2013-14. London: National Health Service, 2015.

8. Australian Institute of Health and Welfare. BreastScreen Australia monitoring report 2012-2013. Canberra: Australian Institute of Health and Welfare, 2015. https://www.aihw.gov.au/reports/cancer-screening/breastscreen-australia-monitoring-2012-2013/conte nts/table-of-contents Lest 17.11.2020.

9. Bhargava S, Moen K, Qureshi SA et al. Mammographic screening attendance among immigrant and minority women: a systematic review and meta-analysis. Acta Radiol 2018; 59: 1285-91.

[PubMed][CrossRef]

10. Høydahl E. Innvandrere og norskfødte med innvandrerforeldre i Oslo. Rapporter 2014/23. Oslo: Statistisk sentralbyrå, 2014 .

https://www.ssb.no/befolkning/artikler-og-publikasjoner/_attachment/184456?_ts=146dc7agego Lest 17.11.2020.

11. Le M, Hofvind S, Tsuruda K et al. Lower attendance rates in BreastScreen Norway among immigrants across all levels of socio-demographic factors: a population-based study. J Public Health 2019; 27: 229-40. [CrossRef]

12. Bhargava S, Akslen LA, Bukholm IRK et al. Performance measures among non-immigrants and immigrants attending BreastScreen Norway: a population-based screening programme. Eur Radiol 2019; 29: 4833-42. [PubMed][CrossRef]

13. Hofvind S. red. Cancer in Norway 2016. Special Issue: The Norwegian Breast Cancer Screening Program, 1996-2016: Celebrating 20 years of organised mammographic screening. Oslo:

Kreftregisteret, 2017.

https://www.kreftregisteret.no/globalassets/cancer-in-norway/2016/mammo_cin2016_special_issue_ web.pdf Lest 17.11.2020.

14. Statistisk sentralbyrå. Slik definerer SSB innvandrere.

https://www.ssb.no/befolkning/artikler-og-publikasjoner/slik-definerer-ssb-innvandrere/ Lest 28.8.2020.

15. Bray F, Ferlay J, Soerjomataram I et al. Global cancer statistics 2018: GLOBOCAN estimates of incidence and mortality worldwide for 36 cancers in 185 countries. CA Cancer J Clin 2018; 68:394-424. [PubMed][CrossRef]

16. Leinonen MK, Campbell S, Ursin G et al. Barriers to cervical cancer screening faced by immigrants: a registry-based study of 1.4 million women in Norway. Eur J Public Health 2017; 27: 873-9. 
[PubMed][CrossRef]

17. Abebe DS. Public health challenges of immigrants in Norway: a research review. Oslo: Nasjonalt kompetansesenter for migrasjons- og minoritetshelse, 2010.

https://www.fhi.no/globalassets/dokumenterfiler/rapporter/2010/public-health-challenges-of-immigr ants-in-norway-nakmireport-2-2010.pdf Lest 17.11.2020.

18. Diaz E, Calderón-Larrañaga A, Prado-Torres A et al. How do immigrants use primary health care services? A register-based study in Norway. Eur J Public Health 2015; 25: 72-8. [PubMed][CrossRef]

19. Johansen PA. Hver tredje koronapasient ved sykehus i Norge ble født i et annet land. Aftenposten 17.7.2020.

https://www.aftenposten.no/norge/i/7obkbK/hver-tredje-koronapasient-ved-sykehus-i-norge-ble-foedti-et-annet-land Lest 4.11.2020.

20. Gabrielsen E, Lundetræ K. Hvor godt forstår voksne nordmenn skriftlig helseinformasjon? Sykepleien 2014; 1: 26-34. [CrossRef]

21. Statistisk sentralbyrå. Familier og husholdninger, 1. januar 2016.

https://www.ssb.no/befolkning/statistikker/familie/aar/2016-10-28?fanetabell\&sortnummer\&tabell $=281875$ Lest 4.11 .2020 .

22. Statistisk sentralbyrå. Befolkningens utdanningsnivå, 1. oktober 2013.

https://www.ssb.no/utdanning/statistikker/utniv/aar/2014-o6-19?fanetabell\&sort-

nummer\&tabell=181252 Lest 4.11.2020.

Publisert: 1. februar 2021. Tidsskr Nor Legeforen. DOI: 10.4045/tidsskr.20.0134

Mottatt 16.2.2020, første revisjon innsendt 29.8.2020, godkjent 17.11.2020.

(C) Tidsskrift for Den norske legeforening 2020. Lastet ned fra tidsskriftet.no 